\title{
Análisis jurídico-administrativo del programa Préstamos Renta Universidad
}

A legal-administrative analysis of a student loan program in Spain

\author{
Miguel Ángel Andrés Llamas \\ Profesor Asociado de Derecho \\ Constitucional \\ Dpto. Derecho Constitucional, \\ Procesal y Eclesiástico del Estado \\ Universidad de Valladolid, España \\ E-mail:miguelangel.andres@uva.es \\ mllamas@usal.es
}

\begin{abstract}
Resumen: El Gobierno de España creó el programa Préstamos Renta Universidad para financiar los estudios de posgrado. En la primera convocatoria (2007), los estudiantes sólo tenían que devolver el dinero prestado si ingresaban una cantidad superior a 22.000 euros anuales. Sin embargo, en sucesivas convocatorias se eliminó el umbral de devolución. A raíz de la crisis económica, numerosas personas no pueden hacer frente al pago de los préstamos. El diseño del programa Préstamos Renta Universidad es complejo: intervienen el Ministerio de Educación, el Instituto de Crédito Oficial y entidades de crédito colaboradoras. En la ejecución de este programa han existido numerosos problemas relacionados con la información administrativa. La naturaleza jurídica de los préstamos y el procedimiento de concesión también son cuestiones complejas. Finalmente, se examinan las medidas urgentes que el Gobierno ha adoptado para solucionar el problema.
\end{abstract}

Palabras clave: políticas públicas, subvenciones, procedimiento administrativo, educación, endeudamiento estudiantil. 


\begin{abstract}
The Government of Spain established the Renta-Universidad Loan Program to finance postgraduate studies. In the first call (2007), students only had to return the borrowed money whether they earned more than 22,000 euros per year. However, in successive calls, the referred return threshold was eliminated. As a result of the economic crisis, many of these students have not been able to return the loans. The design of the Renta-Universidad Loan Program is complex (the Ministry of Education, the Official Credit Institute and several credit entities collaborating with the administration are involved) and there have been numerous problems related to administrative information. The legal nature of these loans and the granting procedure are complex issues as well. Finally, the urgent measures the Government has recently adopted to solve this problem are analysed.
\end{abstract}

Keywords: public policies, state aid, administrative procedure, education, student debt.

\title{
1. Origen y evolución del programa Préstamos Renta Universidad
}

En 2007, el Ministerio de Educación del Gobierno de España puso en marcha el programa público Préstamos Renta Universidad al objeto de financiar las enseñanzas de máster -con posterioridad, también de doctorado-, que adquirían carácter oficial en el marco del Proceso de Bolonia. Los escasos estudios referidos a este programa público se han realizado desde un enfoque económico, bien para examinar los resultados de eficiencia y equidad (CalladoMuñoz et al., 2017), bien para proponer un modelo alternativo (Cabrales et al., 2018).

Debido a la propia tradición epistémica del campo del Derecho, no abundan los análisis jurídicos que podríamos llamar de caso en relación con políticas públicas concretas. Por otro lado, los estudios de políticas públicas no priorizan los enfoques jurídicos. El presente trabajo pretende evaluar el desempeño de un programa público desde una perspectiva jurídico-administrativa. Se pretende poner el foco en aspectos jurídicos a fin de constatar su incidencia en el desarrollo y eficacia de las políticas públicas.

El programa de préstamos universitarios se insertó desde su creación en la política pública de ayudas al estudio. Los préstamos se configuraban como verdaderos préstamos renta, es decir, préstamos cuya devolución estaba condicionada a la obtención por el titulado 
universitario de una renta futura. En concreto, el capital sólo se reembolsaba una vez la persona prestataria alcanzase ingresos anuales de 22.000 euros.

Sin embargo, entre otras modificaciones, en posteriores convocatorias el umbral de renta desapareció, por lo que los préstamos tenían que devolverse aun cuando el titulado universitario careciera de ingresos. Las convocatorias anuales se aprobaron mediante una serie de órdenes ministeriales: Orden ECI/1702/2007, de 12 de junio, por la que se regulan los préstamos a graduados universitarios ligados a la posesión de una renta futura; Orden CIN/2940/2008, de 14 de octubre, por la que se regulan los préstamos ligados a la posesión de una renta futura para realizar estudios de Máster Universitario; Orden EDU/3108/2009, de 17 de noviembre, por la que se regulan los préstamos ligados a la posesión de una renta futura para realizar estudios de posgrado de Máster Universitario o de Doctorado; y Orden EDU/3248/2010, de 17 de diciembre, por la que se regulan los préstamos universitarios para realizar estudios de posgrado de máster y de doctorado.

El número total de préstamos concedidos fue de 15.621, mientras que el importe total ascendió a la cantidad de 220.325.041 euros. Las convocatorias de préstamos delimitaban los plazos de carencia y amortización y los importes máximos. Así, para un máster de un solo curso académico, el capital máximo se cifró en 6.000 euros, pudiendo añadirse una renta mensual de 800 euros. La siguiente tabla, elaborada a partir de las Órdenes ministeriales y de datos ofrecidos por el Gobierno de España en respuesta a preguntas parlamentarias, recoge las principales características de las distintas convocatorias: 


\begin{tabular}{|c|c|c|c|c|}
\hline & 2007 & 2008 & 2009 & 2010 \\
\hline Número de préstamos & 3.463 & 4.742 & 5.181 & 2.235 \\
\hline Presupuesto $(€)$ & 50.000 .000 & 150.000 .000 & 150.000 .000 & 100.000 .000 \\
\hline Importe concedido & 42.342 .339 & 72.573 .733 & 74.908 .162 & 30.500 .807 \\
\hline Importe promedio $(€)$ & $12.227,07$ & $15.304,46$ & $14.458,24$ & $13.646,89$ \\
\hline Niveles & Máster & Máster & $\begin{array}{l}\text { Máster } \quad \text { y } \\
\text { doctorado }\end{array}$ & $\begin{array}{l}\text { Máster y } \\
\text { doctorado }\end{array}$ \\
\hline $\begin{array}{l}\text { Duración aproximada } \\
\text { (años) }\end{array}$ & $\begin{array}{l}2 \text { de carencia y } 8 \text { de } \\
\text { amortización }\end{array}$ & $\begin{array}{l}10 \text { de carencia y } 10 \text { de } \\
\text { amortización }\end{array}$ & $\begin{array}{l}6 \text { de carencia y } 7 \\
\text { de amortización }\end{array}$ & $\begin{array}{l}2 \text { de carencia } \\
\text { y } 4 \text { de } \\
\text { amortización }\end{array}$ \\
\hline Umbral de renta $(€)$ & 22.000 & Inexistente & Inexistente & Inexistente \\
\hline Extinción de deuda & A los 15 años & Inexistente & Inexistente & Inexistente \\
\hline Tipo de interés & $0 \%$ & $0 \%$ & $0 \%$ & Fijo (ICO) \\
\hline Amortización & Trimestral & Mensual & Mensual & Mensual \\
\hline
\end{tabular}

Además de las Órdenes mencionadas, el programa de préstamos contó con una última convocatoria aprobada mediante la Orden EDU/3320/2011, de 1 de diciembre, por la que se regulan los préstamos universitarios para realizar estudios de posgrado de Máster y de Doctorado. Para esta convocatoria los fondos públicos se redujeron y las condiciones se endurecieron aún más. Llama la atención la antinomia contenida en el articulado de esta Orden ministerial. Por un lado, su artículo 3.5 determinaba "un interés fijo equivalente al tipo de interés medio de la última emisión de deuda, con vencimiento similar al del préstamo, realizada previa a la entrada en vigor de la Orden”, mientras que el artículo 8.1 disponía la aplicación de un tipo de interés fijo del 5,433\%, un desliz que tuvo que ser corregido por la Orden ECD/250/2012, de 31 de enero, por la que se modifica la Orden EDU/3320/2011. El Gobierno decidió suprimir esta última convocatoria mediante la Orden ECD/630/2012, de 28 de marzo, por la que se deja sin efectos la Orden EDU/3320/2011, de 1 de diciembre, por la que se regulan los préstamos universitarios para realizar estudios de posgrado de Máster y Doctorado, y su modificación realizada por Orden ECD/250/2012, de 31 de enero.

La rápida derogación de esta convocatoria impidió que más estudiantes suscribieran préstamos con condiciones gravosas. Las razones esgrimidas en la exposición de motivos de la propia Orden de supresión ponen de relieve algunas de las disfunciones del programa, 
constatando un "progresivo deterioro de las condiciones de los préstamos universitarios" y admitiendo que "los préstamos de esta línea tenían una doble característica que los hacía difícilmente asumibles por los estudiantes: menor tiempo de amortización que en convocatorias anteriores y un elevado interés fijo para toda la vida del préstamo". Asimismo, en respuesta de 26 de junio de 2013 a pregunta parlamentaria (184/023653) formulada en el Congreso de los Diputados, el Gobierno evaluó el programa de préstamos de manera claramente negativa: "Sin lugar a dudas, la complejidad de estas ayudas y el poco éxito que obtuvo el proyecto anterior, junto con las dificultades que ahora salen a la luz, nos obliga a aprender de los errores y ofrecer soluciones óptimas para las necesidades reales de los estudiantes".

La clave de bóveda de la problemática que plantea el programa Préstamos Renta Universidad radica en la desaparición del umbral de devolución en sucesivas convocatorias. El préstamo-renta es un instrumento de política pública utilizado para financiar el acceso del alumnado a las enseñanzas universitarias, ya sea de forma exclusiva o en combinación con los tradicionales sistemas de becas. La Administración interviene para que el acceso a los estudios universitarios no dependa de la situación socioeconómica personal o familiar, de tal forma que la devolución del importe del préstamo se halla condicionada a la obtención de ingresos futuros por el alumnado. Únicamente en el supuesto de que tras la obtención del título universitario los alumnos superen un determinado nivel de ingresos, deberán devolver el dinero prestado.

En el ámbito de la economía de la educación suelen compararse las propiedades de equidad y eficiencia de los préstamos-renta en relación con los sistemas de becas (Moreno Becerra, 2008). Se argumenta que un sistema de préstamos-renta tiene mejores propiedades de eficiencia que las becas porque promueve un uso económico más racional de los recursos, incentiva el rendimiento académico y promueve la autofinanciación del sistema de ayudas; a la vez, se atribuyen propiedades de equidad ya que la devolución está sujeta a la renta percibida, se elimina la dependencia familiar del estudiantado y, en cuanto al debate sobre la progresividad o regresividad del gasto, se apunta que los contribuyentes dejan de sufragar el coste de la educación recibida por quienes realmente se benefician. Por el contrario, existen argumentos que desaconsejan el uso del préstamo-renta desde parámetros de 
equidad y justicia social. Así, la renta neta de los titulados universitarios (la renta bruta menos los reembolsos de la deuda contraída) podría no ser mucho mayor que la renta bruta de quienes carecen de dicha titulación, por lo que habría menos incentivos para formarse; la devolución del préstamo opera, en términos de política fiscal, como un impuesto proporcional sobre la renta en tanto que se aplicaría un tipo fijo de la renta futura que grava más a los que menos recursos económicos tengan (quienes más se endeudaron); y, finalmente, se repara en que este sistema de préstamos-renta carece de un flujo redistributivo de la riqueza, ya que el sistema se autofinancia entre generaciones de universitarios, independientemente del nivel económico de los distintos grupos sociales. Sin perjuicio de que los sistemas de becas constituyen una obligación pública de trascendencia constitucional, los préstamos-renta son un instrumento de ayuda al estudio que no supone un riesgo de endeudamiento comparable al de los meros préstamos.

Ahora bien, el préstamo-renta no debe confundirse con el contrato de préstamo regulado en el Código Civil o, si se dan las notas características, con el contrato de crédito al consumo previsto en la Ley 16/2011, de 24 de junio, de contratos de crédito al consumo. El préstamo es un contrato en el que una de las partes entrega una cantidad de dinero que debe ser reembolsado en el plazo establecido con o sin pacto de pagar intereses. El capital del préstamo puede emplearse para adquirir una vivienda, un automóvil o un título universitario. La finalidad del préstamo no es una característica definitoria del contrato de préstamo. Por tanto, si una cantidad de dinero se entrega a un estudiante para financiar sus estudios de máster o doctorado pero la devolución del capital no está ligada a la obtención de una renta futura, no estamos ante un instrumento de ayuda al estudio, sino ante un contrato de préstamo o, más en concreto, ante un contrato de crédito al consumo.

Por ejemplo, en un contrato de crédito al consumo, prestamista y, en su caso, intermediario, tienen la obligación de explicar al consumidor de manera personalizada las características del producto, la información precontractual necesaria y los riesgos en caso de impago o de endeudamiento. Se trata, como reza el Preámbulo de la Ley 16/2011, de 24 de junio, de contratos de crédito al consumo, de que la persona prestataria "pueda comprender las repercusiones del contrato de crédito en su situación económica”.

Un préstamo es una operación de riesgo. Un estudiante que en el futuro no tenga ingresos se verá 
endeudado antes de haberse siquiera incorporado al mercado de trabajo. Un préstamo para financiar estudios universitarios es una operación que puede conllevar al estudiante a una situación de endeudamiento excesivo o sobreendeudamiento e incluso a la exclusión social.

En este sentido, cabe apuntar que la concesión de créditos por parte del sector privado para financiar los estudios universitarios se ha incrementado en los últimos años, una tendencia explicable "por un aumento generalizado de las tasas universitarias y, en segundo lugar, por la necesidad de especializarse mediante masters y estudios de postgrado con elevados precios que obligan a los estudiantes a acudir al mercado del crédito para poder afrontar su pago" (ADICAE, 2015, 66). A pesar de esta tendencia, en España no existe una normativa sectorial que regule estas modalidades de préstamos mercantiles.

La distinción es clara: el préstamo-renta es un instrumento enmarcado en las políticas públicas de ayuda al estudio; un préstamo o crédito al consumo conlleva riesgos de impago o endeudamiento. Sin embargo, a pesar de la desaparición del umbral de renta, la Administración proporcionó el mismo tratamiento jurídico e informativo en todas las convocatorias del programa Préstamos Renta Universidad. A modo de ejemplo, la confusión puede advertirse en el propio título de la Orden EDU/3108/2009, de 17 de noviembre, por la que se regulan los préstamos ligados a la posesión de una renta futura para realizar estudios de posgrado de Máster Universitario o de Doctorado. El rótulo se refiere a préstamos ligados a la posesión de una renta futura a pesar de que el umbral de devolución, en puridad, ha desaparecido.

El desarrollo del programa Préstamos Renta Universidad coincidió con la gran recesión económica, que disparó los niveles de desempleo juvenil y precariedad laboral. Desde muy pronto comenzaron los impagos. Y el umbral de renta no estaba allí.

\section{Actores, naturaleza jurídica y procedimiento de concesión}

Las situaciones de impago provocaron nuevos problemas asociados a la compleja arquitectura jurídico-administrativa del programa. Esta complejidad deriva, en buena medida, de la pluralidad de actores implicados en la concesión de los préstamos: principalmente, el Ministerio de Educación, el Instituto de Crédito Oficial (ICO) y las entidades de crédito colaboradoras. 
El Ministerio de Educación se configura como el órgano concedente de los préstamos. El programa Préstamos Renta Universidad es un programa netamente público. El 9 de marzo de 2007, el Ministerio de Educación y Ciencia presentó al Consejo de Ministros un Informe sobre las políticas de becas, préstamos y ayudas al estudio que abarcaba el plan de préstamos educativos ligados a la renta futura. Con este programa, tal y como se exponía en la Orden de la primera convocatoria, el Ministerio pretendía ayudar a los jóvenes titulados universitarios que desearan obtener un máster a fin de financiar los estudios y otros gastos personales vinculado con el objetivo de "facilitar el incremento del nivel de educación de los ciudadanos como uno de los requisitos imprescindibles para un desarrollo económico sostenible, para la mejora de la equidad social y el bienestar de los ciudadanos en la sociedad del conocimiento".

El ICO es una entidad pública empresarial que tiene naturaleza de entidad de crédito y consideración de agencia financiera del Estado. De acuerdo con la disposición adicional trigésima cuarta de la Ley 30/2005, de 29 de diciembre, de Presupuestos Generales del Estado, desde el 1 de enero de 2006, habrán de ser instrumentados a través del ICO los préstamos o líneas de financiación en apoyo de las personas físicas o jurídicas de carácter privado que requiera la intervención de una entidad de crédito, financiados con cargo a créditos del capítulo 8 de los Presupuestos Generales del Estado. También prevé este precepto que las condiciones de instrumentación para cada tipo de préstamo o línea de financiación se concretarán en el oportuno Convenio de colaboración entre el ICO y el Departamento Ministerial que tenga asignado el crédito del capítulo 8 de los Presupuestos, suscribiéndose los convenios de manera anual para la instrumentación de las correspondientes líneas de financiación. Estas previsiones se materializaron durante la ejecución del programa Préstamos Renta Universidad, suscribiéndose los correspondientes convenios anuales.

A su vez, cada línea de financiación se instrumenta mediante contratos de financiación firmados entre el ICO y las entidades financieras adheridas. De acuerdo con lo previsto en los convenios suscritos entre el Ministerio y el ICO, las obligaciones de las entidades de crédito eran las siguientes: recibir las autorizaciones de los préstamos y tramitar la formalización; abonar en la cuenta del cliente el importe del capital prestado; gestionar los 
importes mensuales reembolsados por los clientes e ingresarlos anualmente al ICO; y enviar al ICO la relación de clientes con impagos. El Instituto de Crédito Oficial rechazó entregar estos contratos de financiación mediante resolución de 25 de septiembre de 2018 debido a que el acceso a la información supondría un perjuicio para los “intereses económicos y comerciales" del ICO y de las Entidades de Crédito, mencionando la Directiva (UE) 2016/943, del Parlamento Europeo y del Consejo, de 8 de junio, relativa a la protección de los conocimientos técnicos y la información empresarial no divulgados (secretos comerciales) contra su obtención, utilización y revelación ilícitas. Además, el ICO también alegó que los contratos están protegidos por confidencialidad y que no existe autorización de las Entidades de Crédito colaboradoras. En cualquier caso, cabe presumir que los bancos tenían como principal incentivo para sumarse a este programa la posibilidad de incrementar su cartera de clientes.

Como se ha dicho, los préstamos-renta deben concebirse como un instrumento de ayuda al estudio diferente a los contratos de préstamo, a pesar de que la Administración proporcionó en todas la convocatorias un mismo tratamiento jurídico e informativo. ¿Pero cuál es la naturaleza jurídica de los préstamos del programa público más allá de aquella conceptualización?

En primer lugar, hay que remarcar el carácter público del programa Préstamos Renta Universidad. Los fondos del programa son públicos: los préstamos se financian con cargo a créditos del capítulo 8 (activos financieros) de los Presupuestos Generales del Estado. Por tanto, el riesgo de las operaciones es asumido exclusivamente por el Ministerio de Educación, que tiene la condición de prestamista. El rol del ICO y de las entidades de crédito colaboradoras es meramente instrumental.

En consecuencia, el Ministerio es el órgano encargado de gestionar a través de la Agencia Tributaria el cobro de las cantidades impagadas, ya que las cuotas tienen la consideración de derechos de naturaleza pública de la Hacienda estatal. Así se desprende de lo establecido en el artículo 8.6 de la Orden ministerial de 2008: "La falta de pago de las cuotas dentro de los noventa días naturales siguientes a la fecha de amortización, determinará el inicio del período ejecutivo, en los términos que legalmente se establezcan y con los efectos previstos en la Ley 47/2003, de 26 de noviembre, General Presupuestaria, la Ley 58/2003, de 17 de 
diciembre, General Tributaria y demás normativa que resulte de aplicación”. En sentido similar, en el art. 8.6 de la Orden ministerial de 2009 se dispone que "las cantidades derivadas del reintegro del préstamo tendrán la consideración de derechos de naturaleza pública de la Hacienda pública estatal, sujetos a su regulación específica”.

Más aún, en el Convenio de colaboración entre el Ministerio de Educación y el Instituto de Crédito Oficial de diciembre de 2009 consta la obligación que tiene la entidad de crédito colaboradora de "enviar al ICO con la periodicidad que se determine, la relación de clientes con impagos totales o parciales, a efectos de que el ICO lo remita al ME [Ministerio de Educación] para que éste gestione, a través de la Agencia Tributaria, el cobro de las cantidades impagadas". A pesar de la claridad de estas previsiones, lo cierto es que, ante la proliferación de situaciones de impago, las entidades financieras colaboradoras han realizado, entre otras prácticas problemáticas, gestiones directas de cobro. Incluso una entidad presentó una demanda ejecutiva de título no judicial por impago. Tras la oposición de la persona prestataria, la entidad desistió y fue condenada en costas (vid. Auto de la Audiencia Provincial Civil de Madrid, Sección 19a, de 13 de febrero de 2019, rec. 793/2018).

Si desde la perspectiva jurídico-financiera las cantidades a reembolsar son derechos de naturaleza pública de la Hacienda Pública estatal, la naturaleza de los Préstamos Renta Universidad desde la perspectiva jurídico-administrativa resulta menos explícita. La actividad crediticia pública no ha sido excesivamente regulada ni conceptualizada por la doctrina más allá de un enfoque subjetivista (Jiménez Blanco, 2018). En todo caso, aquí se defiende que los Préstamos Renta Universidad tienen naturaleza jurídica subvencional. Existen remisiones a la normativa general en materia de subvenciones en algunas Órdenes de convocatoria y, también, en la Resolución de 27 de diciembre de 2013, de la Secretaría General de Universidades, por la que se dictan instrucciones para el cumplimiento de lo dispuesto en la disposición adicional cuadragésima primera de la Ley 22/2013, de 23 de diciembre, de Presupuestos Generales del Estado para el año 2014.

Aun cuando el artículo 2.4 h) de la Ley 38/2003, de 17 de noviembre, General de Subvenciones excluye el crédito oficial del concepto de subvenciones, la figura del Préstamo Renta Universidad encaja en la noción de "Créditos concedidos por la 
Administración a particulares sin interés, o con interés inferior al de mercado" prevista en la Disposición adicional sexta de la citada Ley General de Subvenciones, unos créditos que en ausencia de normativa específica se regulan "por las prescripciones de esta ley que resulten adecuadas a la naturaleza de estas operaciones, en particular, los principios generales, requisitos y obligaciones de beneficiarios y entidades colaboradoras, y procedimiento de concesión".

En consonancia con su naturaleza jurídica subvencional, el procedimiento de concesión de los Préstamos Renta Universidad se enmarca en la institución del procedimiento administrativo. A grandes rasgos, el procedimiento administrativo diseñado para la concesión de los préstamos consta de tres fases: iniciación, autorización y formalización. En cuanto a la iniciación, la solicitud a instancias del interesado debía dirigirse al Ministerio de Educación por vía exclusivamente telemática. La autorización correspondía al Ministerio, y consistía en un documento electrónico llamado “Ticket-Autorización”. La formalización era la única fase que se desarrollaba ante la Entidad de Crédito Colaboradora y el único trámite que tenía lugar de manera presencial. A pesar de que en las Órdenes ministeriales no constaba ninguna exigencia de elevación del documento de formalización a escritura pública, las entidades de crédito colaboradoras sí lo ordenaron, asumiendo los estudiantes los correspondientes gastos notariales. Una vez formalizada la operación, la Entidad de Crédito remitía al ICO la petición de fondos.

La existencia de un auténtico procedimiento administrativo es del todo incuestionable. Ahora bien, su diseño puede tildarse de confuso, fragmentado y técnicamente deficiente. Entre otros defectos, la regulación del procedimiento no aclara cuál es el acto administrativo definitivo, si la autorización o el documento de formalización. A pesar del empleo del término "autorización", el documento de formalización es el que produce los efectos para la notificación de las liquidaciones tributarias. Pareciera que la Administración está atribuyendo a una entidad privada el ejercicio de una función pública como es la dictar un acto administrativo definitivo (Galán Galán y Prieto Romero, 2010).

Lo cierto es que el Ticket-Autorización lleva aparejados efectos jurídicos como, por ejemplo, la facultad de aplazar el pago de los precios públicos por servicios académicos hasta la percepción del préstamo. Si se entiende que la formalización es un trámite 
meramente accesorio realizado ante un tercero (la entidad colaboradora), la autorización ministerial implicaría la celebración de una suerte de contrato de préstamo a distancia, planteándose la posibilidad de aplicar la Ley 22/2007, de 11 de julio, sobre comercialización a distancia de servicios financieros destinados a los consumidores, que también concierne a proveedores públicos.

\section{Las medidas de protección a las personas prestatarias}

Desde el inicio de los períodos de amortización, numerosas personas prestatarias, en su mayoría jóvenes con problemas para insertarse en una realidad laboral marcada por el elevado desempleo y la precariedad, experimentaron dificultades para asumir la devolución de los préstamos. De acuerdo con la respuesta escrita del Gobierno de España a la pregunta parlamentaria sobre la morosidad en el programa de préstamos universitarios (184/034119), “al cierre del ejercicio 2017, según la información facilitada desde las distintas Entidades Financieras que suscribieron préstamos al amparo de estas Líneas de Financiación, existen 13.311 operaciones con saldo vivo por importe de 139,62 millones de euros, en las cuatro convocatorias que fueron abiertas para estos préstamos", si bien en cuanto al número de impagos "se informa que el ICO, una vez recibe la información sobre operaciones impagadas por parte de las entidades colaboradoras, da traslado al Departamento ministerial competente, desglosando la información por clientes y corresponde al propio Ministerio realizar las actuaciones de recobro correspondientes a través de la Agencia Tributaria, por lo que, a partir de ese momento, el ICO desconoce el estado de estas gestiones de recobro”.

A fin de defender sus intereses, las personas prestatarias crearon una plataforma de afectados, que posteriormente se constituiría legalmente en la Asociación de Afectados por el Préstamo Renta Universidad, cuyos fines quedaban contemplados en el artículo 3 de sus estatutos con el siguiente tenor: "Solicitar la equiparación de las condiciones de los contratos de las tres últimas convocatorias (2008/2009; 2009/2010; 2010/2011) del Préstamo-Renta con las condiciones del contrato de la primera convocatoria (2007/2008). En concreto las cláusulas referentes al inicio de la amortización del mismo que deberían ir sujetas a un umbral-renta, las referentes a los intereses y demás comisiones, y finalmente la referente a la condonación en casos de extrema gravedad. Y, con carácter general, la 
Asociación tiene como fin el de reparar y mejorar la situación jurídico-económica de los afectados derivada de la contratación del Préstamo-Renta”.

La situación generalizada de dificultad económica propició la aprobación de las primeras medidas de protección a las personas prestatarias. Así, la disposición adicional cuadragésima primera de la Ley 22/2013, de 23 de diciembre, de Presupuestos Generales del Estado para el año 2014 dispuso la ampliación del período de carencia y de amortización de los préstamos concedidos a las personas prestatarias que no superasen en el ejercicio anterior el umbral de ingresos de 22.000 euros, en el marco, exclusivamente, de la Orden EDU/3248/2010, de 17 de diciembre.

La medida alcanzaba a las personas prestatarias de una sola convocatoria y, por su naturaleza, se limitaba a postergar la problemática de los impagos. De tal manera que, a finales de 2016, la Asociación de Afectados por el Préstamo Renta Universidad presentó una reclamación por responsabilidad patrimonial frente al Ministerio de Educación del Gobierno de España.

La reclamación por responsabilidad patrimonial fue formulada por la Asociación de Afectados y, de forma acumulada y simultánea, por más de doscientas personas que se consideraban perjudicadas por la actuación del Ministerio de Educación y las entidades colaboradoras. La viabilidad de reclamaciones de responsabilidad patrimonial con alcance plural o colectivo se contempla en, entre otras previsiones, el artículo 61.4 de la Ley 39/2015, de 1 de octubre, del Procedimiento Administrativo Común de las Administraciones Públicas, que se refiere a la necesidad de individualizar la lesión "en una persona o grupos de personas". Un autor de referencia en materia de responsabilidad, González Pérez (2012, 259), así lo corroboraba: "El sistema de las llamadas class actions puede perfectamente articularse en los procedimientos administrativos de responsabilidad de una Administración pública -que puede incoarse de oficio por la propia Administración, dando al procedimiento publicidad suficiente para que todos los afectados puedan comparecer".

El fundamento esencial de la reclamación colectiva radicaba en el desconocimiento de las personas afectadas de que los préstamos suscritos debían ser reembolsados aun cuando se sobrepasara el umbral de renta. La reclamación articulaba un supuesto de responsabilidad 
patrimonial de la Administración por información errónea, de creciente relevancia en la jurisprudencia y en la doctrina del Consejo de Estado, órgano que exige, junto a los requisitos clásicos de la responsabilidad patrimonial, la concurrencia de tres elementos añadidos: la identidad entre el órgano que causa la lesión y el órgano que informa, la identidad entre reclamante y persona que recibe la información y, finalmente, el carácter formalizado de la información suministrada (Acosta-Penco, 2016).

Paralelamente, la Asociación de Afectados optó por hallar una solución en el ámbito parlamentario en colaboración con el Grupo Parlamentario Confederal de Unidos PodemosEn Comú Podem-En Marea. Así, la Comisión de Educación y Deporte del Congreso de los Diputados, en su sesión de 22 de marzo de 2017, aprobó la Proposición no de Ley relativa a actuaciones a favor de los afectados por los Préstamos Renta Universidad (PNL 161/001101). El Congreso instó al Gobierno, entre otras medidas, a realizar "las actuaciones necesarias para que el reembolso de los préstamos correspondientes a la convocatoria de 2008 y siguientes sólo tenga lugar cuando los prestatarios posean una renta anual de 22.000 euros en cada ejercicio, extinguiéndose la deuda en todo caso a los quince años, en consonancia con las condiciones incorporadas en el sistema de préstamos renta en 2007", así como a "exigir a las entidades financieras colaboradoras el cese de los requerimientos de pago y de las cláusulas y prácticas relativas al cobro de comisiones e intereses moratorios y a la incorporación de datos personales en ficheros de morosidad".

En tanto que el Gobierno de España hizo caso omiso al mandato del Congreso de los Diputados, el citado Grupo Parlamentario presentó la Proposición de Ley por la que se aprueban medidas de apoyo a las personas perceptoras de los Préstamos Renta Universidad. El artículo 3 de esta Proposición de Ley modificaba las condiciones de amortización en el sentido indicado en la Proposición No de Ley aprobada por la Comisión de Educación y Deporte del Congreso de los Diputados.

La negociación derivada de la reclamación por responsabilidad patrimonial, el nuevo clima político que produjo la moción de censura y la tramitación de la citada Proposición de Ley constituyen factores que favorecieron la respuesta positiva del Gobierno, incorporada en el Real Decreto-ley 3/2019, de 8 de febrero, de medidas urgentes en el ámbito de la Ciencia, la Tecnología, la Innovación y la Universidad, convalidado en la última sesión plenaria de 
la XII Legislatura. El Real Decreto-Ley justifica el requisito de la extraordinaria y urgente necesidad del siguiente modo:

Dada la crisis económico-financiera habida a lo largo de los últimos años, muchos de los prestatarios se encuentran ante la imposibilidad de hacer frente a los pagos adeudados en virtud de estos préstamos, lo que requiere de la adopción de medidas urgentes que palien un posible sobreendeudamiento de los estudiantes, de consecuencias extraordinariamente negativas para su solvencia presente y futura, ya que la imposibilidad de hacer frente a los pagos pendientes provoca que los mismos se vean impedidos a la hora de poder suscribir otros instrumentos financieros, realizar determinadas operaciones con entidades de crédito y, en definitiva, avanzar en sus perspectivas económicas y vitales.

La técnica legislativa empleada consistió en la aprobación de una disposición transitoria única, una opción ciertamente cuestionable en tanto que esta disposición no abordaba el tránsito de un régimen jurídico previamente regulado en el articulado. La nueva norma contempla que las personas prestatarias de todas las convocatorias pueden optar, con anterioridad al día 30 de junio de 2019, por la novación contractual. Sin duda, las condiciones que ahora rigen la relación contractual comportan un cambio sustancial en la naturaleza jurídico-económica de los préstamos. El plazo de amortización solo se activará cuando las personas prestatarias superen en el ejercicio anterior el umbral de base imponible general y del ahorro del Impuesto sobre la Renta de las Personas Físicas de 22.000 euros, mientras que el nuevo plazo de devolución de las cantidades adeudadas se fija en quince años desde la novación. Aun cuando la norma no se refiere expresamente a la extinción de la deuda una vez expire el plazo de devolución, la referencia a la interrupción del plazo de amortización permite concluir que transcurridos los quince años desde la novación sin que la persona prestataria haya superado el umbral no será exigible el reembolso del capital prestado.

Asimismo, entre las nuevas condiciones se establece que procederá la amortización de una décima parte del importe pendiente de pago en cada anualidad en la que la persona prestataria supere el umbral de ingresos.

Una de las lagunas más importantes del nuevo régimen jurídico de los préstamos universitarios atañe a las personas prestatarias que en la actualidad superan el umbral de renta de 22.000 pero que en sucesivos ejercicios podrían no alcanzarlo. ¿Tienen derecho estas personas a solicitar la novación en los términos previstos por la disposición transitoria 
única? En estos casos, cabe defender la aplicación analógica de la solución prevista en el Real Decreto-ley 3/2019, de 8 de febrero, a tenor de que, en puridad, no se trata de una disposición transitoria, sino de un nuevo régimen jurídico de los préstamos universitarios. Del mismo modo, no nos hallamos ante una ley de ámbito temporal, pues el Real Decretoley $3 / 2019$, de 8 de febrero, no ha autolimitado su plazo de vigencia. Nos encontramos, pues, ante supuestos en los que concurre la identidad de razón que exige el artículo 4.1 del Código Civil.

\section{Reflexiones finales}

En este artículo se ha analizado el programa Préstamos Renta Universidad poniendo el foco en aspectos jurídicos-administrativos. A la vista de las deficiencias observadas en el tratamiento de la información administrativa, el diseño del procedimiento de concesión o la supervisión de la ejecución, el desarrollo de este programa público puede tildarse de mala práctica administrativa.

En efecto, la desaparición sobrevenida del umbral de devolución resulta difícilmente compatible con el principio de confianza legítima. La configuración del procedimiento administrativo fragmentaba innecesariamente la concesión del préstamo, diluía las responsabilidades y obstaculizaba el ejercicio del derecho a la información. La ausencia de supervisión por parte de la Administración dio pie a prácticas indebidas de las entidades financieras, que carecen de título habilitante para realizar gestiones directas de cobro al tener las cuotas de los préstamos la consideración de derechos de naturaleza pública de la Hacienda pública estatal. En suma, el desempeño de la Administración y sus entidades colaboradoras no parece superar los estándares de diligencia que suelen identificarse en el todavía inconcluso derecho a una buena administración, y ello sin perjuicio de las medidas urgentes que se han adoptado para corregir los "errores" que el propio Gobierno de España llegó a admitir.

Las medidas de corrección de algunos de esos errores administrativos han venido inducidas por una profusa tarea de control parlamentario. Preguntas, proposiciones no de ley e incluso 
una proposición de ley contribuyeron de manera decisiva a la aprobación de la disposición transitoria del Real Decreto-ley 3/2019.

La problemática suscitada por los Préstamos Renta Universidad plantea nuevos desafíos a la hora de abordar la actividad crediticia de la Administración. No puede obviarse que, a pesar de que la Administración esté ofreciendo un préstamo sin interés o con interés inferior al de mercado, este tipo de operaciones conlleva un evidente riesgo de endeudamiento para las personas físicas. Parece sensato considerar que el derecho a una buena administración implica que la Administración tiene un correlativo deber de información sobre los riesgos derivados de los préstamos.

Más aún, desde una perspectiva jurídica, cabe plantear la viabilidad de la aplicación del Derecho de Consumo en este tipo de relaciones. El texto refundido de la Ley General para la Defensa de los Consumidores y Usuarios y otras leyes complementarias, aprobado por el Real Decreto Legislativo 1/2007, de 16 de noviembre, prescribe en su artículo 3 que "son consumidores o usuarios las personas físicas que actúen con un propósito ajeno a su actividad comercial, empresarial, oficio o profesión”, una condición que no se pierde por el hecho de que la persona consumidora se relacione con una Administración pública. No en vano, el artículo 4 de dicho texto refundido considera empresario "a toda persona física o jurídica, ya sea privada o pública", amén de que en el supuesto de los Préstamos Renta Universidad las entidades de crédito colaboradoras intervinieron activamente en los procesos de comercialización.

También en estos casos podría resultar de aplicación la Ley 16/2011, de 24 de junio, de contratos de crédito al consumo, pues si bien esta norma no contempla expresamente la figura del empresario público, debe recordarse el relevante rol de la entidades financieras que operaron como intermediarios de crédito. Ciertamente, la Directiva 2008/48/CE del Parlamento Europeo y del Consejo, de 23 de abril de 2008, relativa a los contratos de crédito al consumo, en su artículo 2.2 1), excluye la aplicación de la Directiva a "los contratos de crédito relativos a préstamos concedidos a un público restringido, en virtud de una disposición legal con un objetivo de interés general, y a un tipo de interés inferior al habitualmente propuesto en el mercado o sin interés o en condiciones que son más favorables para el consumidor que las habituales en el mercado y a un tipo de interés no 
superior al habitualmente propuesto en el mercado". La Ley que la transpone, en cambio, no incorpora esta exclusión. Sobre la posibilidad de considerar los préstamos de la Administración concedidos a particulares como créditos al consumo, hay que tener en cuenta que el artículo 3.f) de la Ley 16/2011, de 24 de junio, de contratos de crédito al consumo excluye su aplicación a los contratos de crédito libres de intereses y sin ningún otro tipo de gastos. Por ejemplo, los préstamos de la Orden EDU/3248/2010, de 17 de diciembre, por la que se regulan los préstamos universitarios para realizar estudios de posgrado de máster y de doctorado sí incorporan pacto de pagar interés. Y, en cuanto a las convocatorias de 2008 y 2009, sería necesario realizar un análisis casuístico de los gastos generados. En todo caso, más allá de la cuestión de la aplicación de estas normas de Derecho de Consumo, sí cabe apuntar la necesidad de que la normativa que rige la convocatoria de este tipo de préstamos incorpore el espíritu tuitivo consumerista para garantizar el derecho a la información y evitar problemas de endeudamiento excesivo o sobreendeudamiento. Más aún, parece razonable plantear la oportunidad de repensar la configuración jurídica de la actividad crediticia de la Administración.

Una última reflexión debe interpelar directamente a las universidades. De un lado, en un sentido general, porque propuestas como la de los préstamos universitarios indefectiblemente se hallan conectadas con la misión y la concepción imperante de la universidad en un Estado Social y Democrático de Derecho. Así lo atisbaban Fernández Liria y Alegre $(2004,238)$ en relación con las reformas inspiradas en el proceso de Bolonia:

Otro criterio a valorar será la demanda de ingreso por parte de los estudiantes que acceden a la Universidad, pero, al mismo tiempo, se trata a toda costa de cambiar su perfil: al dejar de considerarse la educación un derecho que nos corresponde dada nuestra condición de ciudadanos y haber pasado a considerarse un servicio al que podemos acceder dada nuestra condición de consumidores, es importante sustituir al estudiante vocacional por el estudiante inversor (es decir, aquel que accede a la Universidad con la intención de rentabilizar la cualificación allí obtenida). En esta dirección juega un papel importante la sustitución que se está produciendo de becas por créditos (a bajo interés mientras duran los estudios pero cuyos intereses aumentan al ingresar en el mercado laboral). Es decir, la demanda de ingreso como criterio de calidad, se refiere a la demanda por parte de estudiantes previsiblemente endeudados que, por la cuenta que les trae, ya se encargarán de demandar algo que el mercado les vaya a remunerar. 
De otro lado, las propias universidades contribuyeron a difundir las convocatorias de los

Préstamos Renta Universidad. Y, más en concreto, fue en el seno de los campus universitarios donde de manera mayoritaria las entidades financieras allí ubicadas publicitaron y comercializaron los préstamos aquí glosados; y todavía hoy lo hacen con otros préstamos privados ideados para financiar el acceso a los estudios universitarios. El riesgo de sobreendeudamiento estudiantil, que tantos problemas ha ocasionado otras latitudes, aún no ha desaparecido.

\section{Referencias bibliográficas}

Acosta-Penco, T. (2016): “La responsabilidad patrimonial de la Administración por información errónea en la doctrina del Consejo de Estado", Revista Digital de Derecho Administrativo, 15: 233-264. http://dx.doi.org/10.18601/21452946.n15.11

ADICAE (2015): La realidad del crédito no hipotecario en España. Análisis económico y jurídico del crédito al consumo y los créditos rápidos. [30-06-2019]. Disponible en web: http://publicaciones.adicae.net/publicaciones/descarga.php?art=831

Cabrales, A., Güell, M., Madera, R. y Viola, A. (2018): "Income Contingent University Loans: Policy Design and an Application to Spain”, Fedea Policy Papers, 6. Disponible en web: http://documentos.fedea.net/pubs/fpp/2018/07/FPP2018-06.pdf

Callado-Muñoz, F. J., Del Rey Cantelli, E. y Utrero-González, N. (2017): “Estimating taxpayer subsidies and individual repayment burdens of a student loan program in Spain", Hacienda Pública Española, 220 (1): 89-106. http://dx.doi.org/10.7866/HPE-RPE.17.1.3

Fernández Liria, C. y Alegre Zahonero, L (2004): “La revolución educativa. El reto de la Universidad ante la sociedad del conocimiento", Logos: Anales del Seminario de Metafísica, 37: 225-256.

Galán Galán, A. y Prieto Romero, C. eds. (2010): El ejercicio de funciones públicas por entidades privadas colaboradoras de la Administración. Barcelona: Huygens.

González Pérez, J. (2012): Responsabilidad patrimonial de las Administraciones públicas. Pamplona: Thomson Reuters. 
Jiménez Blanco, G. y Torrecilla Pérez, J. (2018): “El régimen jurídico del crédito oficial”, en Garcés Sanagustín y Palomar Olmeda, A. eds.: Derecho de las subvenciones y ayudas públicas: 929-956. Pamplona: Thomson Reuters Aranzadi.

Moreno Becerra, J. L. (2008): Economía de la educación. Madrid: Pirámide. 